\title{
Low Hemoglobin among Pregnant Women in Midwives Practice of Primary Health Care, Jatinangor, Indonesia: Iron Deficiency Anemia or $\beta$-Thalassemia Trait?
}

\author{
Ari Indra Susanti, ${ }^{1}$ Edhyana Sahiratmadja, ${ }^{2}$ Gatot Winarno, ${ }^{3}$ Adhi Kristianto Sugianli, \\ Herman Susanto, ${ }^{3}$ and Ramdan Panigoro ${ }^{2}$ \\ ${ }^{1}$ Program Study of Midwifery, Division of Maternal and Child Health, Department of Public Health, Faculty of Medicine, \\ Universitas Padjadjaran, Bandung, Indonesia \\ ${ }^{2}$ Department of Biochemistry and Molecular Biology, Faculty of Medicine, Universitas Padjadjaran, Bandung, Indonesia \\ ${ }^{3}$ Department of Obstetrics and Gynecology, Faculty of Medicine, Universitas Padjadjaran and Dr. Hasan Sadikin General Hospital, \\ Bandung, Indonesia \\ ${ }^{4}$ Department of Clinical Pathology, Faculty of Medicine, Universitas Padjadjaran and Dr. Hasan Sadikin General Hospital, \\ Bandung, Indonesia \\ Correspondence should be addressed to Edhyana Sahiratmadja; e.sahiratmadja@unpad.ac.id
}

Received 1 February 2017; Revised 22 March 2017; Accepted 18 April 2017; Published 29 May 2017

Academic Editor: Duran Canatan

Copyright (C) 2017 Ari Indra Susanti et al. This is an open access article distributed under the Creative Commons Attribution License, which permits unrestricted use, distribution, and reproduction in any medium, provided the original work is properly cited.

Low hemoglobin $(\mathrm{Hb})$ or anemia is common among pregnant women in developing countries which may cause adverse pregnancy outcomes and maternal deaths. Our study aimed to assess $\mathrm{Hb}$ level measured by midwives in primary health care facility at rural area of Jatinangor, Indonesia, and to explore whether the anemia was due to iron deficiency (IDA) or $\beta$-thalassemia trait ( $\beta$-TT). Pregnant women $(n=105)$ had finger prick test for $\mathrm{Hb}$ level during a regular antenatal care examination from October to November 2016. Hb level by finger prick test was compared with venous blood, measured by complete blood count (CBC). Indices including $\mathrm{MCV}$ and MCH and indices of Shine \& Lal, Mentzer, Srivastava, Engels \& Frase, Ehsani, and Sirdah were analyzed to differentiate anemia due to IDA and anemia due to suspect $\beta$-TT. HbA2 was measured to confirm $\beta$-TT. Anemic pregnant women were found in $86.7 \%$ by finger prick test compared to $21.9 \%(n=23)$ by CBC. The prevalence of $\beta$-TT in our study was $5.7 \%$. Hb measurement among pregnant women in low resource area is highly important; however, finger prick test in this study showed a high frequency of anemia which may lead to iron oversupplementation. A standard $\mathrm{CBC}$ is encouraged; MCV and MCH would help midwives to identify $\beta$-TT.

\section{Introduction}

Iron deficiency is the leading nutrient deficiency in the world, resulting in iron deficiency anemia (IDA) that affects infants, young children, and women of child-bearing age [1]. In pregnancy, lower hemoglobin occurs as a physiological phenomenon especially in the second trimester. Iron need is increased as a result of higher iron demand to accommodate the requirement of fetal placental unit [2]. Since anemia in pregnancy may lead to adverse pregnancy outcomes and maternal deaths [3], iron supplementation and proper nutrition are needed to fulfill the iron deficiency in pregnancy [4].
Iron deficiency is not the only etiology of anemia in the developing countries. Other coinfections, for example, helminthes, tuberculosis, and HIV, or other diseases such as diabetes mellitus may exist [5]. Interestingly, iron deficiency has a protective role for malarial infection, and iron supplementation in this malarial endemic area may thus increase the infection susceptibility [6]. Therefore, a good control of anemia in low- and middle-income countries needs to be considered [7]. Furthermore, low $\mathrm{Hb}$ can be caused by hemoglobinopathies, especially in area where thalassemia trait prevalence is high [8]. Individuals with thalassemia carrier may 
have enough iron due to erythropoiesis by hepcidin suppression, and excessive iron supplementation may subsequently increase the risk for various complications [9]. Whether the anemia in pregnancy in this area is due to iron deficiency or other causes needs to be further explored.

In areas with limited resources, anemia in pregnancy has been often examined by low cost test, which is an incredibly useful tool, that is, capillary finger-pricked test. On the other hand, in area where thalassemia prevalence is high, thalassemia trait is performed with inexpensive tool that has a good validity test, including Naked Eye Single Tube Red Cell Osmotic Fragility Test (NESTROFT) [10]. NESTROFT is, however, sometimes not possible to be done in the field because it needs some preparation. Other tools that can predict thalassemia trait are venous complete blood count (CBC) indices, which vary from indices using $\mathrm{RBC}, \mathrm{MCV}$, and $\mathrm{MCH}$ parameters, including Shine \& Lal, Mentzer, Srivastava, Engels \& Frase, Ehsani, and Sirdah index, to indices using RDW parameter including Green \& King index [11]. In the case of pregnant women, $\mathrm{HbA} 2$ level is used to predict $\beta$-thalassemia trait $(\beta-\mathrm{TT})$ [12]. The definitive differential diagnosis between $\beta$-TT and IDA can be based on the result of HbA2 electrophoresis, serum iron levels, and a ferritin calculation [13].

In Indonesia, the prevalence of anemia among pregnant women is declining over the time, but the number is still as high as more than $35 \%$ [14]. Since this country is located in the thalassemia belt, exploring thalassemia carrier in anemic pregnant women especially by midwives in limited source setting becomes an important issue. Midwives play a major role in antenatal care in the primary health care facility in rural area. Iron tablets are often prescribed without proper blood examination but by recognizing clinical symptoms [15]. This study aimed to explore the hemoglobin $(\mathrm{Hb})$ level among pregnant women measured by midwives in the primary health care facility in rural area of West Java Province, Indonesia. The etiology of anemia in pregnancy was also assessed whether the anemia was due to iron deficiency or $\beta$-TT.

\section{Materials and Methods}

2.1. Pregnant Women Inclusion. The study was conducted using cross-sectional analytic comparative design. All pregnant women who visited the primary health care facility at Jatinangor, West Java, between October and November 2016 were invited to take part in this study after consent. In brief, while waiting in the waiting room for a regular antenatal care, the pregnant women and their husbands were given information about anemia including the possibility and the effect of anemia due to IDA and $\beta$-TT in the pregnancy. Known diseases such as diabetes mellitus and positive HIV were excluded.

2.2. Anemia Status Measurement and Hemoglobin Analyses. The anemia status $(\mathrm{Hb}$ level $<11 \mathrm{~g} / \mathrm{dL})[16]$ of pregnant women was determined from capillary blood from a finger-pricked test (EasyTouch ${ }^{\circledR} \mathrm{GCHb}$ ) by midwives who had a preeducated
TABLE 1: Characteristics and distribution of anemia among pregnant women $(n=105)$ in Jatinangor Puskesmas, West Java, Indonesia, using finger prick and $\mathrm{CBC}$ methods.

\begin{tabular}{lcc}
\hline & Finger prick & CBC \\
\hline Hb value $(\mathrm{g} / \mathrm{dL}) ;$ mean $(\mathrm{SD})$ & $9.5(1.4)$ & $11.7(1.1)$ \\
Anemia status; $n(\%)$ & $91(86.7 \%)$ & $23(21.9 \%)$ \\
Mild (Hb: $8-11 \mathrm{~g} / \mathrm{dL})$ & 75 & 23 \\
Moderate $(\mathrm{Hb}: 6.5-8 \mathrm{~g} / \mathrm{dL})$ & 16 & - \\
\hline
\end{tabular}

Note. CBC, complete blood count; Hb, hemoglobin; SD, standard deviation.

finger-pricked technique according to Indonesian Ministry of Health document $(\mathrm{MOH}$, number 43, 2013). After signing the informed consent form, venous blood samples were drawn and stored at $2-8^{\circ} \mathrm{C}$ before being transported to Dr. Hasan Sadikin General Hospital, Bandung. The distance between the primary health care facility and the hospital was approx. $50 \mathrm{~km}$ and the time between the blood draw and measurement was about 4 hours. Automated hematology analyzer with impedance method for complete blood count (CBC) measurement (Sysmex XP-100, Japan) was used to measure 8 parameters including $\mathrm{Hb}$, mean corpuscular volume (MCV), and red blood count (RBC). Various indices were calculated including index of Shine \& $\mathrm{Lal}\left(\mathrm{MCV}^{2} * \mathrm{MCH} / 100\right)$, Mentzer $(\mathrm{MCV} / \mathrm{RBC})$, Srivastava $(\mathrm{MCH} / \mathrm{RBC})$, Engels \& Frase $(\mathrm{MCV}-\mathrm{RBC}-(5 * \mathrm{Hb}))$, Ehsani $(\mathrm{MCV}-10 * \mathrm{RBC})$, and Sirdah (MCV-RBC $-3 * \mathrm{Hb}$ ), with cut-off of IDA and suspect $\beta$-TT as shown in Table 1. To confirm $\beta$-TT, hemoglobin capillary electrophoresis was performed to measure $\mathrm{HbA} 2$ levels (MG300, Sebia, France). Elevated HbA2 level ( $\geq 3.5 \%$ ) was designated as $\beta$-TT. Study protocol had been reviewed and ethical clearance was granted by Ethical Committee of Faculty of Medicine, Universitas Padjadjaran, number 453/UN6.C1.3.2/KEPK/PN/2016.

2.3. Statistical Analyses. Data was collected into paper-based form and inputted into predesigned Excel sheet (Microsoft Corp., USA). The data distribution of CBC result was tested for normality using Shapiro-Wilk test; when the test pointed out that $p$ value was $>0.05$, the mean and standard deviation were calculated and when $p$ value was $<0.05$, the median and min-max value were calculated.

Characteristics of the pregnant women were described and the frequencies of anemia using finger prick test and $C B C$ were tabulated and compared; $p$ value was considered significant when $p<0.05$ (Student's $t$-test). Concordance of $\mathrm{Hb}$ level between finger prick test and $\mathrm{CBC}$ test and also between various indices and $\mathrm{HbA} 2$ analyses were calculated to determine Cohen's kappa value [17]. Analyses were performed on STATA 12.0 (Stata Corp., Texas, USA).

\section{Results}

3.1. Anemia Prevalence in Pregnancy. In total, there were 105 pregnant women included in this study with median age of 29 (range: 18-39) years. The finger prick test's result showed that $91(86.7 \%)$ pregnant women had anemia, of whom $71.4 \%$ had mild anemia $(\mathrm{Hb}>8 \mathrm{~g} / \mathrm{dL})$ and $15.2 \%$ had moderate anemia 
TABLE 2: Anemia status among pregnant women $(n=105)$ in Jatinangor Puskesmas, West Java, Indonesia, stratified by gravidity and trimester of pregnancy.

\begin{tabular}{lccc}
\hline & $\begin{array}{c}\text { Anemia } \\
N=23\end{array}$ & $\begin{array}{c}\text { Not anemia } \\
N=82\end{array}$ & $p$ value \\
\hline Gravidity & & & \\
Primigravida & 7 & 23 & \\
Multigravida (2-3) & 12 & 47 & \\
Grand multigravida $(\geq 4)$ & 4 & 12 & 0.997 \\
Trimester & & & \\
(1) $(<12$ weeks $)$ & - & 10 & \\
(2) $(12-26$ weeks $)$ & 7 & 35 & $0.021^{*}$ \\
(3) $(>26$ weeks) & 16 & 37 & \\
\hline
\end{tabular}

Note. ${ }^{*} p$ value was set as $<0.05$ (Spearman's correlation).

(Hb: $6.5-8 \mathrm{~g} / \mathrm{dL}$ ). Interestingly, while using $\mathrm{CBC}$ method, mild anemia was found in only $23(21.9 \%)$ women (Table 1$)$. There was, thus, a significant difference in frequency of anemia in pregnant women using finger prick test and $\mathrm{CBC}$, that is, $86.7 \%$ and $21.9 \%$, respectively, and this discordance result in both measurements had an agreement level (Cohen's kappa) of 0.056 , which was very poor. Since the anemia prevalence using $\mathrm{CBC}$ was around the national prevalence of anemia published earlier [14], we used the CBC value for further analyses.

Anemia status in pregnant women was shown according to the gravida and pregnancy trimester (Table 2). There was a correlation between trimester and anemia status; that is, anemia was more prevalent in later stage of pregnancy $(p=$ 0.021 , Spearman's correlation), while there was no correlation between anemia status and the number of gravidas ( $p=$ 0.997).

3.2. Analyses of Complete Blood Count Indices. Further analyses of anemic pregnant women $(n=23)$ using CBC showed that single parameter of $\mathrm{MCV}<76 \mathrm{fL}$ and $\mathrm{MCH}<24 \mathrm{pg}$ and index of Shine \& Lal could detect suspect $\beta$-TT for 5,6 , and 7 pregnant women, respectively, compared to other indices which could detect much lower number (Table 3 ). A total of 6 pregnant women had $\mathrm{HbA} 2$ result of $>3.5$, of whom 5 had $\beta$-TT and 1 was suspected as having probably $\mathrm{HbE}$ because the $\mathrm{HbA} 2$ result was very high. The $\mathrm{HbA} 2$ result indicated that the prevalence of $\beta$-TT in our study among pregnant women was at least $5.7 \%$. Interestingly, when the CBC indices were compared with $\mathrm{HbA} 2$ analyses, discordance results were found with Cohen's kappa ranging from 0.20 to 0.25 , which had a fair quality of agreement. Since the number of anemic pregnant women was low $(n=23)$, we did not calculate the sensitivity and specificity between both $\mathrm{CBC}$ indices and $\mathrm{HbA} 2$ analyses.

\section{Discussions}

During a regular antenatal care in the primary health care facility in a rural area in Jatinangor, Indonesia, $\mathrm{Hb}$ level is measured to control the well-being of both mother and baby.
TABLE 3: Concordant result of $\mathrm{CBC}$ indices to $\mathrm{HbA} 2$ electrophoresis among pregnant women $(n=23)$ in Jatinangor Puskesmas, West Java, Indonesia.

\begin{tabular}{|c|c|c|c|c|}
\hline Indices & $\begin{array}{c}\mathrm{HbA} 2 \\
<3.5 \\
(n 17) \\
\end{array}$ & $\begin{array}{c}\mathrm{HbA} 2 \\
\geq 3.5 \\
(n 6) \\
\end{array}$ & Total & $K$ \\
\hline \multicolumn{5}{|l|}{ RBC count } \\
\hline IDA $<5$ & 17 & 5 & 22 & 0.228 \\
\hline Susp. $\beta$-TT $>5$ & - & 1 & 1 & \\
\hline \multicolumn{5}{|l|}{$\mathrm{MCV}^{*}$} \\
\hline IDA $>76$ & 15 & 3 & 18 & 0.232 \\
\hline Susp. $\beta$-TT $<76$ & 2 & 3 & 5 & \\
\hline \multicolumn{5}{|l|}{$\mathrm{MCH}^{*}$} \\
\hline IDA $>24$ & 14 & 3 & 17 & 0.203 \\
\hline Susp. $\beta$-TT $<24$ & 3 & 3 & 6 & \\
\hline \multicolumn{5}{|l|}{ Shine \& $\mathrm{Lal}^{*}$} \\
\hline IDA $>1530$ & 13 & 3 & 16 & 0.251 \\
\hline Susp. $\beta$-TT $<1530$ & 4 & 3 & 7 & \\
\hline \multicolumn{5}{|l|}{ Mentzer } \\
\hline IDA $>13$ & 17 & 5 & 22 & 0.228 \\
\hline Susp. $\beta$-TT $<13$ & - & 1 & 1 & \\
\hline \multicolumn{5}{|l|}{ Srivastava } \\
\hline IDA $>38$ & 17 & 5 & 22 & 0.228 \\
\hline Susp. $\beta$-TT $<38$ & - & 1 & 1 & \\
\hline \multicolumn{5}{|l|}{ Ehsani } \\
\hline IDA $>15$ & 17 & 5 & 22 & 0.228 \\
\hline Susp. $\beta$-TT $<15$ & - & 1 & 1 & \\
\hline \multicolumn{5}{|l|}{ Sirdah } \\
\hline IDA $>27$ & 17 & 5 & 22 & 0.228 \\
\hline Susp. $\beta$-TT $<27$ & - & 1 & 1 & \\
\hline \multicolumn{5}{|l|}{ Engels Fraser } \\
\hline IDA $<0$ & 17 & 6 & 23 & n.d. \\
\hline Susp. $\beta$-TT $>0$ & - & - & - & \\
\hline
\end{tabular}

Note. Susp. $\beta$-TT, suspect $\beta$-thalassemia trait; IDA, iron deficiency anemia; $K$, Cohen's kappa. ${ }^{*}$ The indices with high suspect $\beta$-thalassemia trait cases. Formula to calculate indices as shown in the bracket: index of Shine \& Lal $\left(\mathrm{MCV}^{2} * \mathrm{MCH} / 100\right)$, Mentzer (MCV/RBC), Srivastava (MCH/RBC), Engels Frase (MCV - RBC - (5* Hb)), Ehsani (MCV - $10 * \mathrm{RBC})$, Sirdah $(\mathrm{MCV}-\mathrm{RBC}-3 * \mathrm{Hb})$.

Our study showed that anemia in pregnancy status measured by midwives using inexpensive and easy to perform capillary finger prick test was very high, reaching almost $90 \%$ of pregnant women. Capillary finger prick test is a simple test to perform; nevertheless, this test requires proper technique. Therefore, the use of finger prick test by midwives in primary health care facility needs to be further reviewed.

When the $\mathrm{Hb}$ level is measured using $\mathrm{CBC}$, result showed that anemia among pregnant women in our study only occurred in around $20 \%$, in line with the national prevalence of anemia published earlier [14]. The discrepancy result shown using finger prick test and standard CBC seems too high and may lead to overprescription of iron supplementation. Iron is indeed needed more in second and third 
semesters as a result of increased fetal placental unit [18]. This conforms to our study, showing that anemia was more prevalent in third semester $(p=0.021)$. Iron deficiency anemia in later phase of pregnancy is associated with the birth weight of the neonates [19] and may play a role as a major killer in pregnant women [7]. Appropriate iron supplementation is needed in pregnancy and WHO has guidelines for iron supplementation in pregnant women and individuals where infection and hemoglobinopathies prevalence are high [1].

The first blood taken in life among healthy individual happens particularly in pregnant women. Study in the neighboring country Thailand showed that the main causes of anemia among pregnant women are IDA and thalassemia carriers [20]. In Indonesia, Thalassemia ranks 6 th for catastrophic diseases; therefore, there is a rising interest to screen thalassemia carrier in the general population. Our study has shown $\beta$-TT prevalence as high as $5.7 \%$, conforming to the national prevalence which is around 6 to $10 \%$. Although the national guidelines for thalassemia trait screening exist [21], thalassemia trait screening in general population is not regularly conducted yet. Moreover, the knowledge about etiology of anemia among pregnant women other than iron deficiency such as hemoglobinopathies is not well known among students midwifery (Sahiratmadja et al., unpublished data), making the question on how to distinguish IDA and thalassemia trait a major concern, especially in the limited resource area. IDA can be diagnosed by simple and easy detection. Red blood cells are smeared in object glass and could be seen as small or microcytic cells with hypochromic color. More accurately, IDA can be diagnosed by calculating the CBC performed by a hematology analyzer. Furthermore, the $\beta$-TT pregnant women are often misdiagnosed as those suffering from iron deficiency anaemia; thus, they are given unnecessary iron medication. In this setting, a reliable screening test becomes a need of the hour for screening purposes.

In meta-analysis study to distinguish individuals with $\beta$-TT and IDA, Hoffmann et al. (2015) have noted that microscopic smear examinations and CBC are difficult to be performed in rural area since the source and personnel to examine the smear are scarce, and CBC analyzer is expensive and not portable [22]. For example, in rural area where equipment or expertise is scarce, One Tube Osmotic Fragility Test (OTOFT) is a simple test that can be done to examine carriers [23]. Interestingly, another study also showed that HbA2 is reliable to measure $\beta$-TT when IDA also coexists [24]. Ideally, $\mathrm{HbA} 2$ is more reliable as indicated to detect $\beta$-TT cases in pregnant women [12], but this measurement is costly. One obstacle in $\mathrm{HbA} 2$ measurement is that $\alpha$-thalassemia could be coinherited with $\beta$-thalassemia, making $\mathrm{HbA} 2$ level have normal value, leading to difficulty in screening $\alpha$-thalassemia using HbA2 level [25]. To confirm the definitive diagnosis, DNA analysis is needed.

Further study needs to be designed to calculate the costeffectiveness screening in primary care [26], that is, the strategy of timing of screening of thalassemia carrier. Whether the screening is more beneficial during premarital screening $[27,28]$ or in young adults [29] needs further exploration. Moreover, knowledge of etiology of anemia among student midwives needs to be strengthened for thalassemia problem.
A simple standard $\mathrm{CBC}$, that is, low $\mathrm{MCV}$ and low $\mathrm{MCH}$, may be of important role to detect carriers and a good training program for the midwives leading the process is urgently required.

Limitation of this study was that iron status was not assessed, as this study was not designed for iron status study, particularly since this study was done in a limited setting area. Other limitation is that low number of anemic pregnant women in our study is considered low; however, the consistent results of the currently used method for $\mathrm{Hb}$, that is, prick test, showed no doubt that the finger prick method has poor reliability.

\section{Conclusion}

Low hemoglobin level by finger prick test measured by midwives showed much higher prevalence of anemia, leading to iron oversupplementation. Since Indonesia is located in thalassemia belt area, a reliable measurement to distinguish anemia of iron deficiency or thalassemia carrier is highly needed. Simple single parameter of $\mathrm{CBC}$ such as $\mathrm{MCV}$ and $\mathrm{MCH}$ would help midwives to identify $\beta$-TT among pregnant women; therefore, wherever it is possible, a standard CBC to detect $\beta$-TT is encouraged.

\section{Disclosure}

Ari Indra Susanti and Edhyana Sahiratmadja are co-first authors.

\section{Conflicts of Interest}

The authors declare that there are no conflicts of interest.

\section{Authors' Contributions}

Ari Indra Susanti, Edhyana Sahiratmadja, Gatot Winarno, Adhi Kristianto Sugianli, Herman Susanto, and Ramdan Panigoro conceived the study and participated in the design and data analyses. Ari Indra Susanti and Edhyana Sahiratmadja were involved in data acquisition. All authors contributed towards drafting and agree to be accountable for all respects of the work. Edhyana Sahiratmadja, Adhi Kristianto Sugianli, Herman Susanto, and Ramdan Panigoro critically reviewed the manuscript. All the authors read and approved the manuscript.

\section{Acknowledgments}

The authors are grateful to all midwives from primary health care Puskesmas, Jatinangor, who participated in this study, especially Ms. Nia Kurniawati and Ms. Lilis Kurniati. Special thanks are due to Nessa Nuriftifa and Alvinsyah Pramono who helped in assisting the presentation of "Anemia in Pregnancy" to the pregnant women and are also due to Depi Setiadi for logistic preparation. Professor Ida Parwati from Dept. of Clinical Pathology, Dr. Hasan Sadikin General Hospital, Bandung, is also thanked for her fruitful and collaborative study. This study was financially supported by Academic Leadership Grant (ALG) for Thalassemia Study. 


\section{References}

[1] World Health Organization (WHO), "Iron deficiency anaemia assessment, prevention, and control: a guide for programme managers," World Health Organization (WHO), Geneva, Switzerland, 2001. http://www.who.int/nutrition/publications/en/ ida_assessment_prevention_control.pdf.

[2] N. A. Alwan and H. Hamamy, "Maternal iron status in pregnancy and long-term health outcomes in the offspring," Journal of Pediatric Genetics, vol. 4, no. 2, pp. 111-123, 2015.

[3] M. Khaskheli, S. Baloch, A. S. Baloch, S. Baloch, and F. K. Khaskheli, "Iron deficiency anaemia is still a major killer of pregnant women," Pakistan Journal of Medical Sciences, vol. 32, no. 3, pp. 630-634, 2016.

[4] R. J. Stoltzfus and M. L. Dreyfuss, "Guidelines for the Use of Iron Supplements to Prevent and Treat Iron Deficiency Anemia," http://www.who.int/nutrition/publications/micronutrients/ guidelines_for_Iron_supplementation.pdf?ua $=1$.

[5] E. M. McClure, S. R. Meshnick, P. Mungai et al., "The association of parasitic infections in pregnancy and maternal and fetal anemia: a cohort study in coastal Kenya," PLoS Neglected Tropical Diseases, vol. 8, no. 2, Article ID e2724, 2014.

[6] L. Sangaré, A. M. van Eijk, F. O. Ter Kuile, J. Walson, and A. Stergachis, "The association between malaria and iron status or supplementation in pregnancy: a systematic review and metaanalysis," PLoS One, vol. 9, no. 2, article e87743, 2014.

[7] S.-R. Pasricha, H. Drakesmith, J. Black, D. Hipgrave, and B.-A. Biggs, "Control of iron deficiency anemia in low- and middleincome countries," Blood, vol. 121, no. 14, pp. 2607-2617, 2013.

[8] R. D. Merrill, A. A. Shamim, H. Ali et al., "High prevalence of anemia with lack of iron deficiency among women in rural Bangladesh: a role for thalassemia and iron in groundwater," Asia Pacific Journal of Clinical Nutrition, vol. 21, no. 3, pp. 416424, 2012.

[9] E. Jones, S.-R. Pasricha, A. Allen et al., "Hepcidin is suppressed by erythropoiesis in hemoglobin e $\beta$-thalassemia and $\beta$-thalassemia trait," Blood, vol. 125, no. 5, pp. 873-880, 2015.

[10] S. Piplani, R. Manan, M. Lalit, M. Manjari, T. Bhasin, and J. Bawa, "NESTROFT - a valuable, cost effective screening test for beta thalassemia traitin north indian punjabi population," Journal of Clinical and Diagnostic Research, vol. 7, no. 12, pp. 2784-2787, 2013.

[11] A. Vehapoglu, G. Ozgurhan, A. D. Demir et al., "Hematological indices for differential diagnosis of beta thalassemia trait and iron deficiency anemia," Anemia, vol. 2014, Article ID 576738, 7 pages, 2014.

[12] Z. Ou, Q. Li, W. Liu, and X. Sun, "Elevated hemoglobin A2 as a marker for $\beta$-thalassemia trait in pregnant women," Tohoku Journal of Experimental Medicine, vol. 223, no. 3, pp. 223-226, 2011.

[13] E. Urrechaga, "Red blood cell microcytosis and hypochromia in the differential diagnosis of iron deficiency and $\beta$-thalassaemia trait," International Journal of Laboratory Hematology, vol. 31, no. 5, pp. 528-534, 2009.

[14] J. S. Barkley, K. L. Kendrick, K. Codling, S. Muslimatun, and H. Pachón, "Anaemia prevalence over time in Indonesia: estimates from the 1997, 2000, and 2008 Indonesia Family Life Surveys," Asia Pacific Journal of Clinical Nutrition, vol. 24, no. 3, pp. 452455, 2015.

[15] P. Bergsjø, B. Evjen-Olsen, S. G. Hinderaker, N. Olekingori, and K.-I. Klepp, "Validity of non-invasive assessment of anaemia in pregnancy," Tropical Medicine and International Health, vol. 13, no. 2, pp. 272-277, 2008.

[16] World Health Organization (WHO), "Haemoglobin concentrations for the diagnosis of anaemia and assessment of severity. Vitamin and mineral nutrition information system (WHO/ NMH/NHD/MNM/11.1)," World Health Organization (WHO), Geneva, Switzerland, 2011. http://apps.who.int/iris/bitstream/ 10665/66914/1/WHO_NHD_01.3.pdf?ua=1.

[17] R. Kwiecien, A. Kopp-Schneider, and M. Blettner, "Concordance analysis: part 16 of a series on evaluation of scientific publications," Deutsches Arzteblatt, vol. 108, no. 30, pp. 515-521, 2011.

[18] A. I. Adanikin, J. O. Awoleke, B. A. Olofinbiyi, P. O. Adanikin, and O. R. Ogundare, "Routine iron supplementation and anaemia by third trimester in a nigerian hospital," Ethiopian Journal of Health Sciences, vol. 25, no. 4, pp. 305-312, 2015.

[19] F. M. Tabrizi and S. Barjasteh, "Maternal hemoglobin levels during pregnancy and their association with birth weight of neonates," Iranian Journal of Pediatric Hematology and Oncology, vol. 5, no. 4, pp. 211-217, 2015.

[20] B. Sukrat and S. Sirichotiyakul, "The prevalence and causes of anemia during pregnancy in maharaj nakorn chiang mai hospital," Journal of the Medical Association of Thailand, vol. 89, supplement 4, pp. S142-S146, 2006.

[21] T. D. Atmakusumah, P. A. Wahidiyat, A. S. Sofro et al., "Health Technology Assessment Indonesia," Dirjen Bina Pelayanan Medik Kementrian Kesehatan Republik Indonesia, 2009. Accessed 12 January 2017. http://www.academia.edu/9564064/ Health_Technology_Assessment_Indonesia.

[22] J. J. M. L. Hoffmann, E. Urrechaga, and U. Aguirre, "Discriminant indices for distinguishing thalassemia and iron deficiency in patients with microcytic anemia: a meta-analysis," Clinical Chemistry and Laboratory Medicine, vol. 53, no. 12, pp. 18831894, 2015.

[23] M. S. Yazdani and S. Ahmed, "An 'on the spot' test for targeted screening in index families of thalassaemia," Journal of the Pakistan Medical Association, vol. 60, no. 7, pp. 521-523, 2010.

[24] M. Verhovsek, C.-C. So, T. O’Shea et al., "Is HbA 2 level a reliable diagnostic measurement for $\beta$-thalassemia trait in people with iron deficiency?" American Journal of Hematology, vol. 87, no. 1, pp. 114-116, 2012.

[25] J. Li, X.-M. Xie, C. Liao, and D.-Z. Li, "Co-inheritance of $\alpha$ thalassaemia and $\beta$-thalassaemia in a prenatal screening population in mainland China," Journal of Medical Screening, vol. 21, no. 4, pp. 167-171, 2014.

[26] S. Bryan, E. Dormandy, T. Roberts et al., "Screening for sickle cell and thalassaemia in primary care: a cost-effectiveness study," British Journal of General Practice, vol. 61, no. 591, pp. e620-e627, 2011.

[27] N. A. AlHamdan, Y. Y. AlMazrou, F. M. AlSwaidi, and A. J. Choudhry, "Premarital screening for thalassemia and sickle cell disease in Saudi Arabia," Genetics in Medicine, vol. 9, no. 6, pp. 372-377, 2007.

[28] H. Hashemizadeh and R. Noori, "Premarital screening of beta thalassemia minor in north-east of iran," Iranian Journal of Pediatric Hematology and Oncology, vol. 3, no. 1, pp. 210-215, 2013.

[29] A. Amato, M. P. Cappabianca, M. Lerone et al., "Carrier screening for inherited haemoglobin disorders among secondary school students and young adults in Latium, Italy," Journal of Community Genetics, vol. 5, no. 3, pp. 265-268, 2014. 


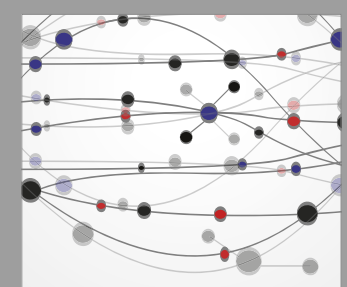

The Scientific World Journal
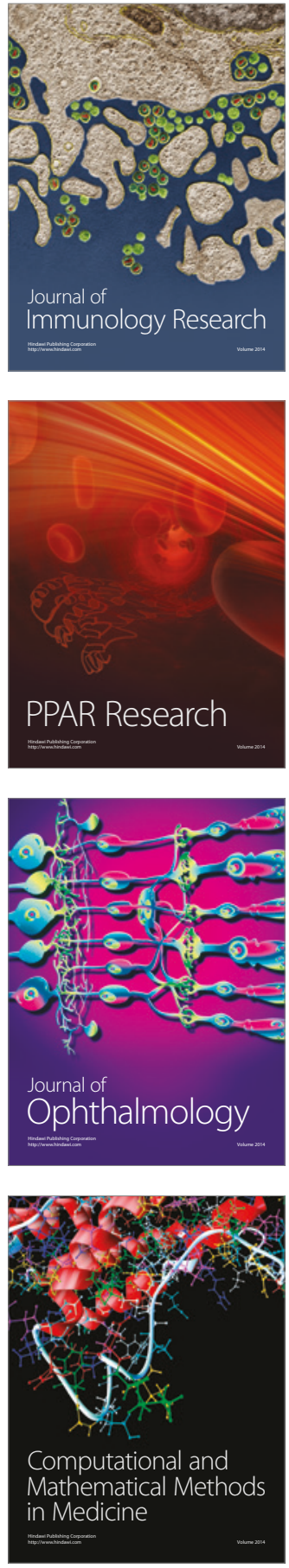

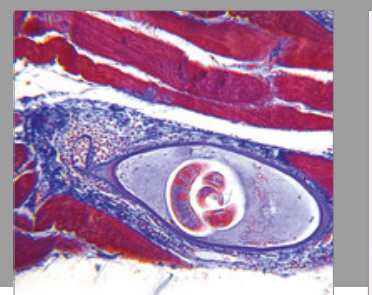

Gastroenterology Research and Practice
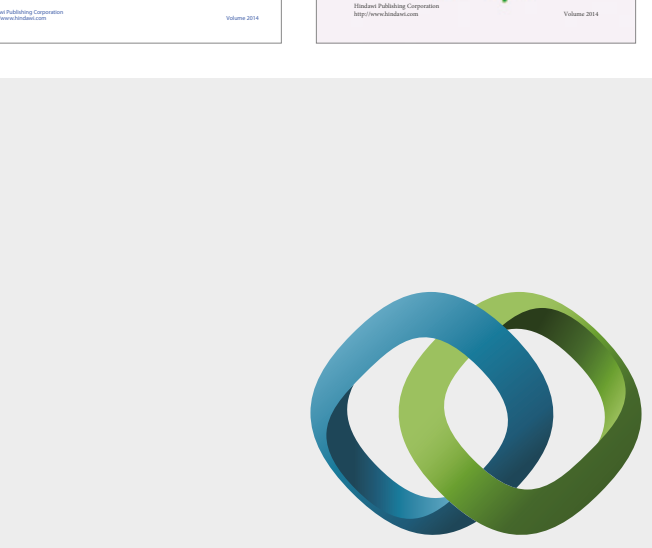

\section{Hindawi}

Submit your manuscripts at

https://www.hindawi.com
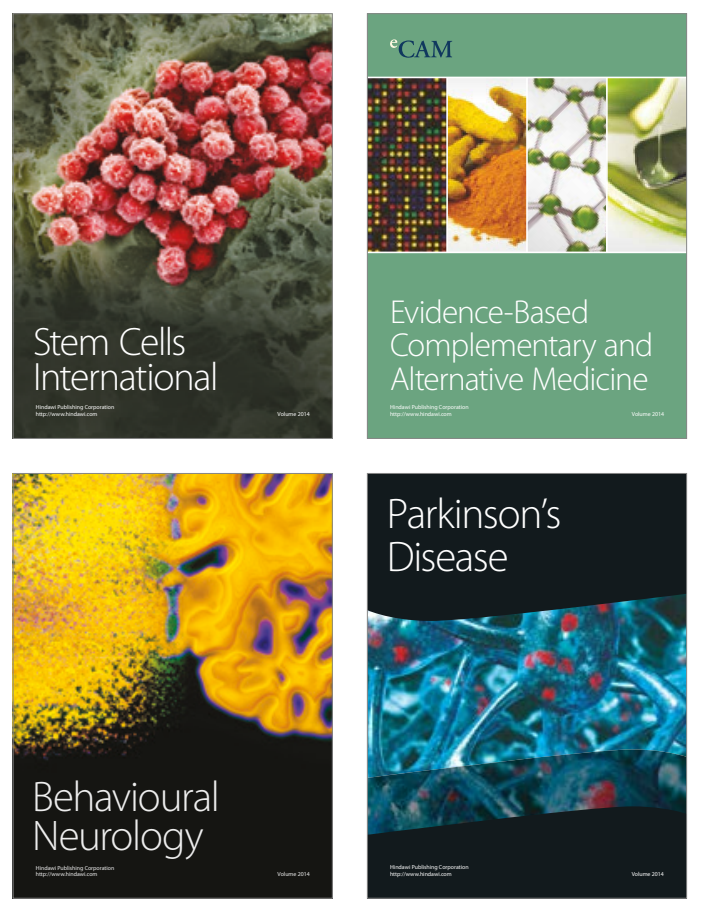
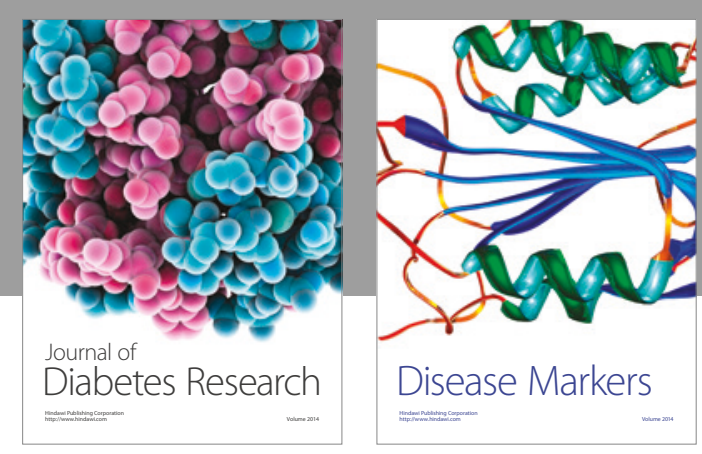

Disease Markers
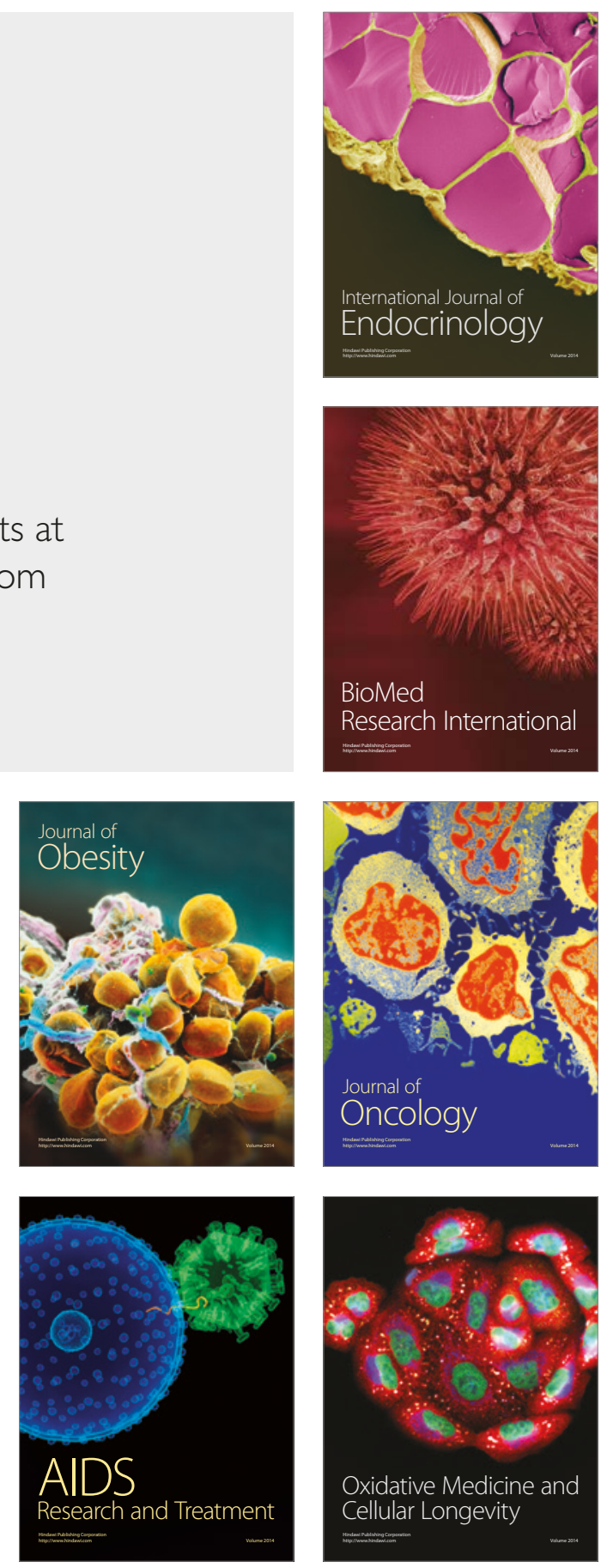